\title{
Os colonos cientistas da América Portuguesa: Questões historiográficas ${ }^{1}$ \\ The scientists settlers of Portuguese America: historiographic issues
}

\author{
Magnus Roberto de Mello Pereira* \\ Ana Lúcia Rocha Barbalho da Cruz ${ }^{* *}$
}

\begin{abstract}
Resumo
No final do século XVIII, uma crescente leva de colonos luso-brasileiros foi estudar na Universidade de Coimbra, que passara por uma reforma de cariz Iluminista ordenada pelo marquês de Pombal. Após concluírem seus cursos, muitos desses estudantes foram contratados pela coroa para estudar as colônias portuguesas da América e da África em moldes científicos. Embora nutrissem amplas expectativas em relação ao 'progresso' e ao desenvolvimento econômico da colônia do Brasil, eles seguiam padrões de lealdade à coroa. Quase todos os letrados formados em Coimbra se consideravam portugueses da América, leais súditos da coroa e estavam diretamente envolvidos na criação de um "Grande Império", no qual coubesse às elites coloniais uma fatia de poder. $O$ presente artigo estuda a recepção historiográfica do fenômeno. Após a independência, a progressiva adoção de princípios nacionalistas para a escrita da história do Brasil provocou a criação de subterfúgios com vistas a transformar esses colonos em "brasileiros", conferindo à sua atuação um caráter nacional, antes mesmo de existir a nação.
\end{abstract}

Palavras chave: Intelectualidade luso-brasileira; Historiografia brasileira; Viajantes

10 presente artigo ampara-se em pesquisas financiadas pela CAPES, pelo CNPq e pela Fundación Carolina. Ele é resultado de uma comunicação apresentada no Seminário Internacional "Nas Rotas do Império: Eixos Mercantis, Tráfico de Escravos, Relações Sociais no Mundo Português", Universidade Federal do Rio de Janeiro, Rio de Janeiro, junho de 2006.

* Professor do Programa de Pós-Graduação da UFPR. Integrante do CEDOPE - Centro de Documentação e Pesquisa de História dos Domínios Portugueses, da Universidade Federal do Paraná. E-mail: magnus@ ufpr.br

** Doutora em História pela UFPR. Integrante do CEDOPE - Centro de Documentação e Pesquisa de História dos Domínios Portugueses, da Universidade Federal do Paraná. E-mail: analucia.cruz@hotmail.com 


\begin{abstract}
At the end of the 18th Century, a growing number of Portuguese-Brazilian colonial subjects were sent to Coimbra University as students, particularly after an Enlightenment prone reformation of the university ordered by the Marquis of Pombal. After finishing their studies, many such students were hired by the Crown to study, in scientific terms, the Portuguese Colonies in South America and Africa. Even though they had many expectations regarding 'progress' and economic development of the Brazilian colony, they followed loyalty patterns to the Crown. Almost every graduate of Coimbra considered himself Portuguese from America, loyal subjects to the Crown and were directly involved in creating a "Great Empire", in which the colonial elites shares the power. This article studies the historiographical reception of this phenomenon. After the Brazilian Independence, the progressive adoption of nationalist principles for the writing of Brazilian history, created a number of subterfuges meant to transform such colonists in "Brazilians", defining their actions as nationalist, even before a nation existed.
\end{abstract}

Keywords: Portuguese-Brazilian intellectuals; Brazilian historiography; Voyagers

A impressionante mobilidade dos portugueses pelo mundo levou o historiador Russel-Wood a caracterizar, com extrema propriedade, o Império Português, de 1415 a 1808, como "um mundo em movimento". ${ }^{2}$ Por mares, terras e rios, um notável "fluxo e refluxo" humano marcou a presença portuguesa no mundo durante quase quatro séculos.

Os personagens sobre os quais se debruça o presente artigo fizeram parte desse imenso contingente de homens em movimento. Trata-se do grupo de brasileiros ${ }^{3}$ que, entre 1772-1808, seguiu para a metrópole em busca de

2 RUSSELL-WOOD, A. J. R. Um mundo em movimento; os portugueses na África, Ásia e América (1415-1808). Algés: Difel, 1998.

3 Como já chamamos a atenção em outros momentos, existe uma polêmica vazia quanto à pertinência ou não do emprego do termo brasileiro para designar os naturais do Brasil no período colonial. À época, para referir os nascidos no Brasil, os termos utilizados eram brasílico, brasiliense, americano, português da América ou, simplesmente, brasileiro, que no século XVIII estava em relativo desuso. Independentemente do termo empregado, as pessoas nascidas nas colônias americanas eram portadoras de uma identidade regional específica, que se definia em contraposição aos portugueses do reino, e na qual estavam contidas outras identidades sub-regionais: baiano, paulista, mineiro, etc. Optou-se por utilizar o termo 'brasileiro' mas é preciso deixar claro que o designativo brasileiro refere-se a uma naturalidade, nascido no Brasil, e não a uma nacionalidade, evidente anacronismo. Sobre essa questão ver PEREIRA, Magnus R. M. e CRUZ, Ana Lúcia R. B. da. Ciência, identidade e quotidiano: alguns aspectos da presença de estudantes brasileiros na Universidade de Coimbra, na conjuntura final do período colonial. Revista de História da Sociedade e da Cultura, Coimbra, v. 9, 2009. p. 205-228. 
instrução, ingressando na Universidade de Coimbra no período pós-Reforma que introduziria nos currículos o ensino das modernas ciências da natureza. ${ }^{4}$ Mesmo nos limites desta baliza cronológica apertada, o percurso dos nascidos no Brasil que ali estudaram exemplifica a trajetória de um grupo peculiar de indivíduos e reflete a inserção portuguesa no intenso fluxo de viagens exploratórias do iluminismo europeu.

O movimento desses integrantes da elite colonial brasileira deu-se em dois sentidos. Inicialmente, partindo da colônia, dirigiram-se à metrópole para estudar na "nova" Universidade de Coimbra, acabada de reformar pelo Marquês de Pombal. Daí, após a formação acadêmica, muitos desses brasileiros fariam um segundo movimento, e, em sentido inverso, juntar-se-iam ao fluxo de portugueses do reino que partiam da metrópole para os territórios coloniais, agora já na qualidade de profissionais a serviço da coroa.

Dos bancos dos novos cursos introduzidos pela reforma da velha Universidade surgia um tipo novo de profissional em Portugal: o naturalista. Personagem paradigmático da Ilustração, ele iria inaugurar uma nova forma de olhar o mundo e, no caso português, contribuir com seus conhecimentos científicos para desvendar as potencialidades econômicas dos produtos da natureza na metrópole e nas colônias.

É relevante notar que, em sua maioria, esses naturalistas eram oriundos das colônias portuguesas da América. Além do que, eram também nascidos no Brasil os matemáticos, médicos e advogados que igualmente vieram a demonstrar especial interesse pelas modernas ciências da natureza, engajando-se na grande aventura de explorar cientificamente a diversidade do mundo natural nos quatro cantos do Império. ${ }^{5} \mathrm{O}$ expressivo número de brasileiros devotados às ciências naturais, muitos deles absorvidos pelo estado português como servidores da coroa ou encarregados de missões científicas específicas, permite pensá-los em termos de uma geração de cientistas-colonos a serviço do Império. ${ }^{6}$ Não é desprezível o fato das viagens filosóficas,

4 Sobre a reforma da Universidade de Coimbra ver PEREIRA, Magnus R. de M.; CRUZ, Ana Lúcia R. B. Ciência e memória: aspectos da reforma da Universidade de Coimbra de 1772. Revista de História Regional, v. 14, 2009. p. 7-48.

5 Sabemos que a palavra cientista não é a mais adequada. 0 termo ideal seria philosophe, empregado por ingleses e americanos para designar a intelectualidade típica do iluminismo. De fato, quase todos os nossos personagens estudaram Filosofia em Coimbra. Em português, todavia, o termo soa um tanto pretensioso. Assim, apesar do anacronismo, optou-se por utilizar, ao longo do texto, termos atuais, como cientista, intelectual, etc.

6 Ver a presença de brasileiros, movimentando-se pela África, a serviço da coroa PEREIRA, Magnus R. de M. e CRUZ, Ana Lúcia R. B. Brasileiros a serviço do Império; a África vista por naturais do Brasil, no século XVIII. Revista Portuguesa de História, v.33, 1999. p.153-190. 
expedições-tipo do iluminismo, realizadas em várias porções do Império, terem sido predominantemente protagonizadas por integrantes desse grupo. É igualmente significativo que vários desses jovens formados em Coimbra tenham-se tornado membros da Academia de Ciências de Lisboa, que congregava eruditos de várias áreas de conhecimento envolvidos na elaboração de propostas de desenvolvimento econômico e cultural para Portugal e suas colônias.

As memórias ${ }^{7}$ encaminhadas para a Academia, as participações, relatórios e diários de viagem, além de volumosa correspondência administrativa, constituem importante acervo resultante do trabalho desses viajantes no reino e no ultramar. Agentes do Império e filhos da Ilustração em Portugal, esses intelectuais brasileiros do século XVIII foram responsáveis não só por produzir informações de primeira mão sobre o mundo colonial, mas por dar feição de planos e projetos a muitas das idéias que articulavam a unidade do mundo português no complexo contexto de sua diversidade cultural e descontinuidade espacial. A atuação dessa geração de cientistas-colonos excedeu em muito os limites do território do Brasil e resultou em vastíssima produção textual; a despeito disso, não despertou maiores atenções dos estudiosos. Curiosamente, um relativo silêncio envolve essas trajetórias. Quando acompanhamos a historiografia brasileira dos últimos dois séculos, a história dessa 'ausência' torna-se bastante visível.

No Brasil monárquico, o Instituto Histórico e Geográfico Brasileiro foi a principal instituição responsável pela construção de uma História Nacional, com iniciais maiúsculas. Seguindo procedimentos historiográficos próprios da época, o IHGB incumbiu-se de criar as grandes efemérides da pátria. Procurou estabelecer, também, o culto à personalidade dos brasileiros que de alguma forma haviam se destacado em qualquer área de atuação, passando a publicar sistematicamente as Biographias dos Brasileiros distinctos por Armas, Letras, Virtudes, \&c. ${ }^{8}$ A criação de um 'Panteão Científico Nacional' foi central ao processo. Diversos institutos regionais, através de suas revis-

7 Por Memórias entendiam-se os textos monográficos de cunho acadêmico ou administrativo. No período estudado, o governo estimulava a produção de memórias que procurassem avaliar as possibilidades econômicas de alguma região ou de alguma atividade agrícola, mercantil ou industrial. Após a fundação da Academia de Ciências de Lisboa, foi criada uma publicação específica para divulgar esta produção, as Memórias Económicas da Academia Real das Sciencias de Lisboa. n.1-5, 1789-1815. (Reedição Banco de Portugal, n.1-5, 1991.)

8 Segundo ENDERS, entre 1839 e 1888, a RIHGB publicou 118 dessas biografias. Sobre a criação do Panteão Nacional pelo IHGB, ver ENDERS, Armelle. "O Plutarco Brasileiro"; A produção dos vultos nacionais no segundo reinado. Revista Estudos Históricos, n.25, 2000. p.43. 
tas, acompanharam esta orientação e publicaram biografias e documentos referentes aos seus âmbitos espaciais de interesse.

Em simultâneo, passaram a ser editadas coleções que podem ser qualificadas como dicionários biográficos e/ou biobibliográficos, que buscavam divulgar a vida e a obra dos personagens ilustres brasileiros. Em 1847, saiu do prelo o Plutarco Brasileiro", de João Manuel Pereira da Silva. Mais tarde, a obra foi republicada e teve o nome trocado para Varões illustres do Brasil durante os tempos coloniais. Com o mesmo espírito, saiu em 1876 o Anno biographico brazileiro, de Joaquim Manoel de Macedo. ${ }^{10}$ Todos esses plutarcos compartiam com o IHGB o tom apologético.

Outra obra da época a abordar a vida e a obra dos homens de letras luso-brasileiros foi o Diccionario Bibliographico, de Inoccêncio Francisco da Silva, que começou a ser editado em Portugal em $1858 .{ }^{11}$ Seria injusto, no entanto, incluir este dicionário na categoria dos plutarcos, pois ela ultrapassa o mero sentido encomiástico que costuma caracterizar tais obras. Sua importância é ter sido a primeira tentativa bem sucedida de fazer um arrolamento geral da produção bibliográfica dos autores de língua portuguesa. o dicionário é ainda hoje uma útil fonte de pesquisa. Para cada autor abordado, Inoccêncio arrola a bibliografia impressa e vai além, apontando a autoria de muitos manuscritos inéditos.

No mesmo período, além das coletâneas, foram editadas biografias mais extensas e mesmo tentativas de avaliação da obra de alguns autores. Veja-se, por exemplo, o opúsculo de José Saldanha da Gama sobre frei Mariano da Conceição Veloso, de $1869 .{ }^{12}$ Todas essas biografias comungavam do propósito de produzir personagens históricos exemplares, obtidos pela limagem de certas arestas inoportunas e pelo acréscimo incessante de adjetivos elogiosos: insigne, notável, eminente, distinto, importante, excepcional!!!

As séries e coletâneas, como os Varões illustres ou o Plutarco Brasileiro, não tinham um caráter especializado e os homens de ciência ali apareciam ao lado de outros personagens considerados exemplares. Assim, o culto mais específico dos cientistas do período colonial foi sendo construído muito

9 SILVA, João Manuel Pereira da. Plutarco Brasileiro. Rio de Janeiro: Eduardo e Henrique Laemert, 1847. 10 MACEDO, Joaquim Manoel de. Anno biographico brazileiro, Rio de Janeiro: Typ. e Lith. do Imperial Instituto Artistico, 1876.

11 SILVA, Innocencio Francisco da. Diccionario bibliographico portuguez. Lisboa: Imprensa Nacional, 18581923. $22 \mathrm{~V}$.

12 GAMA, José Saldanha da. Biographia e apreciação dos trabalhos do botânico brasileiro Frei José Marianno da Conceição Velloso. Rio de Janeiro: Typ. Pinheiro, 1869. 
lentamente como derivação do panteão geral. Um dos primeiros esboços de um panteão nacional dedicado particularmente aos homens de ciências foi elaborado por Varnhagem. Em seu Ensaio histórico sobre as letras no Brasil, de 1847, ao lado de José Bonifácio, figuravam José da Silva Lisboa e José Feliciano Fernandes Pinheiro, futuros viscondes de Cairú e de São Leopoldo, além de José Mariano da Conceição Veloso, Antonio Pires da Silva Pontes e João da Silva Feijó. ${ }^{13}$ Alguns desses personagens conseguiram entronizar definitivamente o santoral pátrio da ciência; outros, nem tanto.

Na Revista do IHGB, foram publicadas biografias do químico Vicente Coelho da Silva Seabra Telles; dos naturalistas José Mariano da Conceição Veloso, Leandro do Sacramento, Alexandre Rodrigues Fereira e José de Sá Bittencourt; dos astrônomos Antônio Pires da Silva Pontes e Francisco José de Lacerda; e dos mineralogistas Manuel Ferreira da Câmara Bittencourt e José Bonifácio de Andrada e Silva. De fato, foram estes os integrantes mais recorrentes do culto nacional aos homens de ciência. Ao lado deles aparece um conjunto de médicos e bacharéis que costumam ser lembrados também por sua atuação científica, ainda que ocasional: Baltazar da Silva Lisboa, José Eloy Otoni, Hipólio da Costa Pereira, etc.

\section{A nacionalização dos heróis da ciência}

A simples observação das biografias desses indivíduos mostra o profundo grau de integração da elite intelectual luso-brasileira na estrutura governativa de Portugal e de suas colônias. O que hoje é uma mera constatação, já foi, no passado, um problema a resolver pelos historiadores. A dificuldade em conciliar a faceta 'portuguesa' com a faceta 'brasileira' da história do Brasil cresceu à medida do tempo decorrido após a independência. Ao longo do século XIX, a historiografia brasileira passou a apoiar-se progressivamente em princípios nacionalistas que insistiam na idéia da exploração colonial desmedida e de uma suposta perseguição e discriminação aos nascidos no Brasil. Assim, os autores oitocentistas viram-se diante da necessidade de criar estratégias para transformar os "portugueses da América", como muitos integrantes da intelectualidade do final do período colonial se auto-designavam, em "brasileiros".

Um dos procedimentos mais correntes adotados pelos biógrafos desses homens de ciência foi dar pouca ênfase ao envolvimento dos biografados

13 VARNHAGEN, Francisco Adolfo de. Ensaio histórico sobre as letras no Brasil [1847] In: Florilegio da poesia brazileira: ou, Collecção das mais notaveis composições dos poetas brazileiros falecidos, contendo as biografias de muitos delles, tudo precedido de um ensaio historico sobre as lettras no Brazil. Rio de Janeiro: Academia Brasileira de Letras: 1946. p.41. 
com os planos e projetos da coroa portuguesa. Isso, quando tais vínculos não eram simplesmente omitidos. As histórias de vida então publicadas insistiam quase sempre num pendor natural dos colonos luso-brasileiros para as ciências, o que tê-los-ia levado à Coimbra. Após passarem rapidamente pela fase da formação universitária em Portugal, os biógrafos costumam apresentar os jovens colonos como atores autônomos, que agiam apenas por desígnios próprios. Desta maneira, a biografia de José Bonifácio conta, que "Em um dos dias do mez de Junho de 1790 deixou as praias portuguezas para, viajando o resto da Europa, adquirir profundos e variados conhecimentos de metallurgia, botânica e chimica" ${ }^{14}$ Nenhuma palavra sobre o fato de que ele era bolsista da coroa portuguesa, que por uma década investiu em sua viagem de formação científica através da Europa. Esta mesma característica está presente na mencionada biografia de frei Veloso, de autoria Saldanha da Gama.

Com perseverança e amor decidido pela sciencia, soffreu Velloso e com resignação algumas enfermidades, que vieram interromper os seus trabalhos; e transpondo o oceano foi em pessoa sujeitar o fructo de suas locubrações ao juizo esclarecido dos homens eminentes da côrte de Lisboa, os quaes receberam-no com aquelle agazalho a que tinha direito incontestavel..$^{15}$

O que o biógrafo não conta é que Conceição Veloso foi levado a Portugal pelo vice-rei D. Luís de Vasconcelos, ansioso por exibir os resultados da missão científica que patrocinara em seu governo. Em Lisboa, Veloso tomou a iniciativa de aproximar-se do ministro D. Rodrigo de Souza Coutinho, com quem estabeleceria uma frutífera parceria. $O$ frade teria, inclusive, mudado da casa do ex vice-rei, onde morava desde que viera para Portugal, para a do ministro. No entanto, a biografia sequer menciona D. Rodrigo.

Quando os vínculos dos biografados com a coroa portuguesa não eram sumariamente suprimidos, ficavam resumidos a uma única frase ou afirmação feita de passagem. Na biografia de Manuel Ferreira da Câmara publicada pelo IHGB, a sua condição de bolsista da coroa portuguesa é dada a conhecer numa pequena e indireta passagem. Câmara enviou à Academia Real das Ciências de Lisboa uma memória sobre as jazidas de carvão mineral da freguesia da Carvoeira, o que teria justificado "a escolha que d'elle fez o governo como pensionario". ${ }^{16}$

14 RHIGB, tomo 8, 1846, p.122.

15 GAMA, op. cit., p.13.

16 RIHGB, tomo 4, 1842, p.515. Num outro trecho da mesma página, a biografia refere-se a Câmara e a José Bonifácio Andrada como "commissionados" da coroa portuguesa. 
Outra fórmula usada reiteradamente para tentar explicar o vínculo dos letrados brasileiros com a coroa foi a de atribuir a esses personagens um conjunto de méritos tão altos que teriam sido suficientes para ultrapassar a perseguição movida pelos portugueses. José Bonifácio, Alexandre Ferreira, e tantos outros, não haviam 'colaborado' com a potência exploradora colonial ${ }^{17}$, mas, por seus próprios méritos, conseguiram 'impor-se' aos portugueses nas mais diversas áreas do conhecimento.

Paulino Nogueira, acadêmico do Instituto do Ceará, ao elaborar a biografia de João da Silva Feijó, atribuiria ao naturalista um merecimento intelectual tão elevado que teria permitido que ele superasse a "arraigada, mas infundada, prevenção da Metrópole contra a Colônia". Apesar dos "máos tempos que então corriam para os naturaes da Colonia brasileira", Feijó teria chegado a tornar-se um cientista brilhante..$^{18}$ Como tem sido reiterado, o pressuposto nacionalista de que a coroa portuguesa desestimulava a formação de uma intelectualidade luso-brasileira não tem o menor fundamento. Toda a carreira científica de Feijó e seus colegas foi fruto da política do estímulo da coroa aos estudantes brasileiros.

Referindo-se à desfiliação de Conceição Veloso da Academia das Ciências, Saldanha da Gama insinua uma perseguição ao frade por envolvimento com movimentos ou idéias pró-independência. ${ }^{19}$

Entretanto será bom lembrar que a presença de um brasileiro tão distincto no gremio de uma sociedade essencialmente portugueza, e em epochas talvez precursoras de grandes abalos que a historia de Portugal menciona, e que a do Brasil commemora com vivo jubilo, poderia ter influido directa ou indirectamente para que se désse o facto [a desfiliação] em que alguns acreditam, e que nós deploramos como brasileiro. ${ }^{20}$

Quase sempre, os biógrafos tentavam explicar que, no fundo, os trabalhos prestados à coroa eram serviços prestados ao Brasil e não a Portugal. É o que diz Varnhagen, ao escrever sobre o astrônomo paulista Lacerda e Almeida e o mineiro Silva Pontes.

17 A palavra 'colonial' está se tornando cada vez mais incômoda na historiografia. Eu diria que a sua atual conotação mais corrente é fruto da operação semântica através da qual os integrantes da elite luso-brasileira conseguiram transitar da condição de colonizadores para a de colonizados.

18 NOGUEIRA, Paulino. O naturalista João da Silva Feijó. Revista Trimensal do Instituto do Ceará, tomo 2, 1888. p.249.

19 Sobre os múltiplos obstáculos à publicação da Flora, de ordem científica inclusive, que redundaram na desfiliação de Veloso, ver NUNES, Maria de Fátima e BRIGOLA, João Carlos. José Mariano da Conceição Veloso (1742-1811), um frade no Universo da Natureza. In: A Casa Literária do Arco do Cego (1799-1801). Lisboa: Imprensa Nacional / Casa da Moeda, 1999. p.60-62.

20 GAMA, op. cit., p.14. 
Foram dois grandes luminares que se apresentaram à disposição do governo da metropole, cheios de fé e de vida, no momento em que, em virtude do tratado de limites celebrado com a Hespanha no $1^{\circ}$ de Outubro d'esse mesmo anno, tanta ia carecer de mathematicos e astronomos. Ora, tratando-se do Brasil, quanto mais natural era que preferisse os brasileiros, e que por seu turno estes preferissem a occasião de prestar serviços á sua propria patria! ${ }^{21}$

Da mesma forma teria agido Frei Leandro do Sacramento, quando recebeu comissões para estudar a flora do Rio de Janeiro. o botânico "não recusou prestar o immenso auxilio de sua inteligencia todas as vezes que o governo do Brasil fez apello ao seu patriotismo". ${ }^{22}$ Alexandre Rodrigues Ferreira teria aceitado integrar a expedição oficial enviada à Amazônia por desejar "prestar serviços mais relevantes ao Estado, á Sciencia, e ao seu paiz natal". ${ }^{23}$

Os pressupostos nacionalistas adotados para dar contorno brasileiro à intelectualidade das colônias americanas também teve impacto na seleção dos relatos de viagem e tratados científicos publicados no período. Existe uma ampla diferença entre o que fora publicado n'O Patriota ${ }^{24}$, por exemplo, e as escolhas editoriais da RIHGB. No periódico científico de antes da independência, a atuação dos lusos-brasileiros em outras colônias era até valorizada. Veja-se a publicação dos relatos de viagem de Joaquim José da Silva em Angola ${ }^{25}$ ou o tratado de João da Silva Feijó sobre Cabo Verde ${ }^{26}$. Após a independência, passaria a vigir orientação exatamente contrária, tanto na RIHGB, quanto em outras iniciativas editoriais. Francisco José de Lacerda e Almeida teve pequena biografia e um de seus relatos publicados pelo IHGB e, em 1841, os seus diários do período da demarcação de fronteiras foram editados em São Paulo. ${ }^{27}$ A opção predominante pela valorização dos textos

21 RIHG, tomo 36, parte 1, 1873, p.177-178.

22 RIHGB, tomo 32, parte 1, 1869, p.186.

23 RIHGB, tomo 2, 1840, p.502.

24 Ver edição digital in: KURY, Lorelai. (org.) Iluminismo e Império no Brasil; O Patriota. (1813-1814) Rio de Janeiro: Editora Fiocruz, 2007.

25 o Patriota. n.1, jan. 1813 e n.2, fev. 1813.

26 Ver reedição integral em PEREIRA, Magnus R. M.; SANTOS, Rosângela M. F. dos. João da Silva Feijó; Um homem de ciência no Antigo Regime português. João da Silva Feijó; Um homem de ciência no Antigo Regime português. Curitiba: Editora da UFPR, 2012. p.942-960.

27 RIHGB, tomo 36, 1873. p. 177-187. ALMEIDA, Francisco José de Lacerda e. Diários de viagem do Dr. Francisco José de Lacerda e Almeida pelas capitanias do Pará, Rio Negro, Mato Grosso, Cuiabá e São Paulo, nos anos de 1780 a 1790. São Paulo: Typ. de Costa Silveira, 1841. . Memoria a respeito dos Rios Baures, Branco, da Conceição, de S. Joaquim, Itomanas e Maxupo e das tres missões da Magdalena, da Conceição e de S. Joaquim. RIHGB, tomo 12, 1849. p. 106-119. 
sobre o Brasil, se confirma no caso de Lacerda e Almeida, ainda que contrariando os desejos de Varnhagen, que aconselhava ao IHGB a publicação dos diários da expedição de travessia da África.

\begin{abstract}
Estes não foram até hoje publicados, nem talvez exista d'elles mais traslados que os que possue em seu archivo o Instituto Historico do Rio, onde ainda em 1868 os vimos e até em duplicado.

Embora de assumpto estranho á chorographia do nosso paiz, sendo obra de um brasileiro que se propozéra a tão gloriosa empreza, não devem considerarse estranhos ao Brasil, pelo que pedimos ao mesmo Instituto que, por gloria sua e do Brasil, faça á historia geographica o serviço de publicar por primeira vez na sua Revista, embora em typos menores e como documento appenso a esta biographia, as observações e notas deixadas por esse eximio paulista, cujos ossos ficaram nos sertões d'Africa. ${ }^{28}$
\end{abstract}

Mesmo defendendo a publicação dos manuscritos africanos, o Visconde de Porto Seguro deixava claro que tais diários eram de significação menor à História do Brasil. Percebe-se, assim, que havia uma clara intenção de nacionalizar a atuação de Lacerda, desconstruíndo ou minimizando a sua faceta 'imperial'. Enquanto isto, em Portugal e na Inglaterra, eram difundidos e traduzidos justamente os textos do astrônomo referentes à sua fracassada tentativa de travessia da África. ${ }^{29}$

\title{
A moderna historiografia brasileira
}

Este panorama sofreu algumas transformações importantes com a República e principalmente a partir do advento do Estado Novo. No entanto, a renovação da historiografia brasileira não implicou em ruptura com o caráter nacionalista preponderante até então. Muito pelo contrário, a idéia de 'construir a nação' ganhou força e premência entre os nossos principais historiadores. O período do "Grande Império" e seus personagens continuava a provocar desconforto entre os estudiosos da história do Brasil, pois conflitava com o viés nitidamente nacionalista, então adotado, que imaginava a passagem da colônia ao Brasil independente de uma forma linear. Aliás, como bem observou Sílvia Hunold Lara, foram Holanda, Prado Jr. e Freyre os principais responsáveis pela consolidação do paradigma, até hoje predominante, segundo o qual a colônia é entendida como um estágio pré-

28 IHGB, tomo 36, 1876, p.183-184.

29 Ver a recente edição completa da documentação referente à viagem empreendida por Lacerda e Almeida na África. PEREIRA, Magnus R. M. e RIBAS, André Akamine. Francisco José de Lacerda e Almeida; Um astrônomo paulista no sertão africano. Curitiba: Editora da UFPR, 2012. 
vio que precede a nação e é esta - o Brasil independente - que lhe confere inteligibilidade. ${ }^{30}$

Tomando Sérgio Buarque de Holanda como exemplo, nota-se que o fenômeno da atuação científica imperial da intelectualidade luso-brasileira do final do período colonial não passou despercebido. O historiador abordou, a partir de alguns pressupostos nada favoráveis, aquilo que ele qualificou de "chusma de naturais do Brasil que então se devotam afincadamente às 'realidades práticas' e às próprias ciências aplicadas". ${ }^{31}$. Para Holanda, tratava-se de uma tendência que se manifestara 'naturalmente' e não como o resultado de uma política coerente orientada a partir de Lisboa. Considerava, ainda, que os integrantes desta camada de brasileiros ilustrados partilhavam idéias retrógradas, derivadas do quadro geral do obscurantismo português. Eram, por exemplo, defensores de um agrarismo arcaico, como o bispo Azeredo Coutinho.

No que diz respeito à edição de fontes históricas, o período pós Revolução de 30 foi marcado pelo estrondoso sucesso literário e historiográfico dos viajantes europeus que percorreram o Brasil a partir da instalação da corte portuguesa no Rio de Janeiro. A coleção Brasiliana, da Cia. Editora Nacional, se encarregou de traduzir e editar dezenas de narrativas destes viajantes, a partir da década de 30. Em 1940, o bibliófilo Rubens Borba deu início a uma coleção concorrente: a Biblioteca Histórica Brasileira, pela Livraria Martins Editora. Mais tarde, a elas somaram-se os relatos editados em parceria da Edusp com a Editora Itatiaia, de Belo Horizonte, e os publicados pelas Edições do Senado Federal. No conjunto, tais coleções bibliográficas seriam responsáveis pelo fenômeno da adoção dos relatos de viajantes como fonte privilegiada pela historiografia brasileira, principalmente a que seria produzida nas Universidades. Essas edições induziram à elaboração de centenas de monografias, dissertações e teses acadêmicas sobre o tema. Não foi por acaso, portanto, que se difundiu a noção de que fora praticamente nula a participação portuguesa, em geral, e luso-brasileira, em particular, no conhecimento científico dos territórios coloniais portugueses. A disponibilidade maciça das narrativas de estrangeiros frente ao desconhecimento geral votado à produção dos luso-brasileiros, praticamente levou a tal equivocada conclusão.

30 LARA, Sílvia Hunold. Conectando historiografias: a escravidão africana e o Antigo Regime na América portuguesa. In: BICALHO, Maria F. e FERLINI, Vera Lúcia A. (orgs.) Modos de governar; Idéias e práticas políticas no Império português. Séculos XVI-XIX. São Paulo: Alameda, 2005. p.21-38.

31 HOLANDA, Sérgio Buarque. Apresentação In: COUTINHO, Joaquim de Azeredo. Obras econômicas de J. J. da cunha Azeredo Coutinho. (1794-1804) São Paulo: Companhia Editora Nacional, 1966. p.14. 
O fenômeno de ofuscamento só não foi total porque, a partir de 30, também foram publicados alguns relatos de viagens de luso-brasileiros, inclusive os referentes à sua presença fora da América portuguesa. Uma das principais iniciativas bibliográficas da época, fruto direto do Estado Novo, foi a Biblioteca Popular Brasileira, editada pelo Instituto Nacional do Livro. O Instituto foi criado pelo ministro Gustavo Capanema, em 1937, e a sua Sessão de Publicações, responsável pela Biblioteca Popular, esteve a cargo de importantes intelectuais da época, como Sérgio Buarque de Holanda e Mário de Andrade. Esta coleção reeditou diversas obras do período colonial e foi nela que encontrou espaço a publicação, em 1944, dos diários de viagem de Lacerda e Almeida, entre os quais os concernentes à tentativa de travessia da África. A Brasiliana também daria espaço a uma narrativa de viagem de autoria de luso-brasileiro na África, a do padre Vicente Ferreira Pires no Daomé ${ }^{32}$. Da mesma forma, a Academia Brasileira de Letras publicou, em 1955, o diário da viagem de Hipólito Ferreira da Costa à Filadélfia ${ }^{33}$. No entanto, tais iniciativas se inscrevem no campo das exceções, incapazes de fazer frente à avassaladora publicação das obras de viajantes estrangeiros que percorreram o Brasil, nos séculos iniciais da colonização e, principalmente, no século XIX. A avalanche foi tão marcante que, até hoje, na historiografia brasileira o termo "viajante", por um processo de metonímia, passou a designar os viajantes europeus e norte-americanos que estiveram no Brasil naquele século.

Sérgio Buarque foi chamado a prefaciar algumas das publicações de relatos e tratados de autoria de luso-brasileiros do século XVIII, como nos casos dos diários de Lacerda e Almeida ou das obras econômicas de Azeredo Coutinho. ${ }^{34}$. No entanto, ele parece ter lidado com essa produção intelectual apenas por dever de ofício, observando-a com maus olhos, como se estivesse marcando posição contra a tendência apologética da historiografia 'positivista' ou dos Institutos. No caso da edição brasileira dos relatos de Francisco José de Lacerda e Almeida, o historiador não foi além de uma apresentação burocrática, na qual aponta que os textos do viajante setecentista eram de

32 PIRES, Vicente Ferreira. Viagem de África em o Reino de Dahomé. São Paulo: Companhia Editora Nacional, 1957

33 PEREIRA, Hipólito. Diário de minha viagem à Filadélfia. Rio de Janeiro: Academia Brasileira de Letras, 1955.

34 COUTINHO, Joaquim de Azeredo. Obras econômicas de J. J. da Cunha Azeredo Coutinho. (1794-1804) São Paulo: Companhia Editora Nacional, 1966. 
“pouca sedução". ${ }^{35}$ Azeredo Coutinho, como já foi mencionado, era considerado um retrógrado escravista. É visível que, para Sérgio Buarque de Holan$\mathrm{da}$, o encantamento com as fontes ficou reservado aos textos de Staden, Thevet, Léry, Marcgrav ou Piso, dos quais ele salta para os relatos dos viajantes europeus do século XIX, caracterizando certo vazio de interesse e prazer de leitura referente ao século XVIII.

Este silêncio eloqüente que envolveu os cientistas nascidos no Brasil setecentista foi quebrado apenas muito raramente, e as raras falas que surgiam tinham antes o intuito de tornar o silêncio ainda mais silencioso. Em 1963, o ornitólogo Olivério Mário Oliveira Pinto, expressou uma noção que ainda hoje é corrente entre os estudiosos da história da ciência no Brasil.

[...] em todo o período colonial, considerando-se como tal o que medeia entre o achamento da terra e a transmigração da Coroa lusitana, difícil será encontrar, digno de referência, qualquer vestígio da participação do Brasil na batalha travada pelo homem, em seu esforço para afastar o véu sob o qual esconde a Natureza os seus segredos. Como conseqüência, é praticamente completa a sua ausência nos registros de que se constitui a história das ciências. ${ }^{36}$

A dimensão e força desta afirmação pode ser sentida quando percebemos que ela foi publicada num dos principais clássicos da nossa historiografia, a História Geral da Civilização Brasileira, organizada justamente por Sérgio Buarque de Holanda. No capítulo das Explorações Científicas, ao qual pertence o excerto acima, a ausência dos brasileiros setecentistas é especialmente notável já que, em seu lugar, ganham destaque mais uma vez aqueles viajantes do século XVI como Hans Staden, André Thevet e Jean de Léry, e do século XVII, Georg Marcgrav e Willem Piso. Quanto aos brasileiros do século XVIII, foram anotadas as contribuições de Frei Mariano da Conceição Veloso, "o primeiro de nossos botânicos”, Alexandre Rodrigues Ferreira, José Bonifácio de Andrada e Silva e seu irmão Martim Francisco de Andrada. Referências que mais confirmam do que suprem a ausência nas páginas da historiografia nacional dos muitos outros que integram a mesma geração.

Aos inúmeros manuscritos de Alexandre Rodrigues Ferreira, à Flora Fluminensis de Conceição Veloso e aos roteiros de visitação do inspetor de minas Martim Francisco Ribeiro de Andrada não se juntaram as memórias de Manuel da Câmara Bethencourt, ou Baltazar da Silva Lisboa, os diários de

35 HOLANDA, Sérgio Buarque de. Apresentação. In: ALMEIDA, Francisco José de Lacerda e. Diários de viagem de Francisco José de Almeida. Rio de Janeiro: Instituto Nacional do Livro, 1944. p.XVI.

36 PINTO, Olivério Mário Oliveira. Explorações científicas. In: HOLANDA, Sérgio Buarque de. (dir.) História geral da civilização brasileira. tomo 1, v.2 Rio de Janeiro: Editora Bertrand Brasil S.A., 7" ed., 1993. p.161. 
viagem de Antônio Pires da Silva Pontes e Francisco José de Lacerda e Almeida referentes à expedição de demarcação de fronteiras ${ }^{37}$, as reflexões sobre as minas de Eloi Otoni, nem os projetos de José Bonifácio de Andrada e Silva ou João Manso Pereira. Se esses brasileiros, e outros tantos, que produziram um conjunto significativo de reflexões sobre o Brasil, não tiveram seus trabalhos destacados, menos ainda foram lembrados aqueles que viajaram e produziram informações sobre outras porções do Império; o que evidenciaria a presença dos cientistas brasileiros no âmbito do universo colonial português.

Entretanto, justamente por tratar-se de obra coletiva, os pontos de vista dos diversos autores que participaram da História Geral nem sempre são coincidentes. No capítulo intitulado Letras e Idéias do Brasil Colonial ${ }^{38}$, Antônio Cândido de Mello e Souza considerava "ainda não ser bem estudado" o fato do grande número de brasileiros, "bem formados", que seguiram os cursos de "matemática, ciências naturais e medicina" na Universidade de Coimbra Reformada, terem-se perdido "para a vida científica, ou não terem tirado dela os frutos possíveis". A multiplicidade de funções que alguns vieram a exercer, transitando "da ciência à política, da especulação à administração" foi apontada com obstáculo à atividade científica dos jovens brasileiros. "Deixando de fora uma excelente segunda linha de estudiosos e divulgadores, que se contam por dezenas", o autor assinalou alguns brasileiros setecentistas que teriam marcado seu tempo, afirmando que "a eles devemos os primeiros reconhecimentos sistemáticos do território, em larga escala, seja do ponto de vista geodésico (Lacerda e Almeida), seja zoológico e etnográfico (Rodrigues Ferreira), seja botânico (Veloso, Leandro), bem como as primeiras tentativas de exploração e utilização científica das riquezas minerais (Vieira Couto, Câmara)". ${ }^{39}$ Rápidas alusões, sem maiores comentários sobre a produção intelectual desses brasileiros, mas, ainda assim, a melhor apreciação geral até então feita sobre o tema.

\section{A historiografia universitária}

A partir dos anos 60, o centro brasileiro de produção historiográfica desloca-se paulatinamente para as universidades, entre as quais sobressaia

37 Esses dois brasileiros tomaram parte na terceira das Partidas, como eram chamadas as expedições demarcadoras de limites, criadas pelos tratados assinados entre Espanha e Portugal para definir as fronteiras de seus territórios coloniais na América do Sul.

38 SOUZA, Antônio Cândido de Mello e. Letras e idéias no Brasil colonial. In: HOLANDA, História Geral. p. 91-105.

39 SOUZA, op. cit. p.101. 
a USP. Nesta nova historiografia universitária a questão do Reformismo Ilustrado teve amplo destaque. Tratava-se de matéria clássica na historiografia portuguesa, mas até então pouco explorada no Brasil. Aqui, no entanto, ela não seria tratada como tema autônomo, mas atrelado ao da independência. Alguns historiadores, no intuito de dar a conhecer o ambiente intelectual das décadas finais do século XVIII e início do século XIX, passaram a debruçar-se sobre o iluminismo em Portugal, deparando-se, por conseqüência, com a atuação da intelectualidade luso-brasileira do período.

Nos quadros desta tendência, a historiadora Maria Odila da Silva Dias chamou a atenção para a geração de brasileiros setecentistas que passara por Coimbra, atentando para as reflexões que seus integrantes vieram a fazer sobre o Brasil. Como declarou nas primeiras linhas de seu artigo, a autora tinha por objetivo "estudar certos aspectos de uma geração que participou da independência" e cujas "atividades de pesquisa e exploração" oferecem interesse para "o estudo das origens de uma cultura brasileira". ${ }^{40}$ Ao traçar uma visão panorâmica da trajetória desses intelectuais, a historiadora quebra o 'silêncio' e acaba por inspirar estudos posteriores, entre os quais o presente artigo. Trata-se de uma obra de ruptura que teve o mérito de se contrapor as certas tendências historiográficas dominantes em sua época. Como pano de fundo, há uma crítica semivelada à propensão de equiparar colonial com atraso. Ao considerar que a abrangência da atuação desses estudiosos ultrapassava os territórios portugueses da América e que os mesmos estavam predominantemente integrados ao processo de reformismo ilustrado conduzido pela coroa portuguesa, ela acerta em dois pontos cruciais das abordagens teleológicas predominantes na historiografia do Brasil colônia.

$\mathrm{O}$ artigo, contudo, não teve maior impacto e tendeu a ficar obscurecido por questões conjunturais. O país vivia um período de profundas tensões políticas e a academia reagiu ideologizando o debate acadêmico. Como bem lembrou a historiadora Ana Burmester, a historiografia da década de 1970, em sua vertente dominante paulista e uspiana, caracterizou-se pela insistência no tema das "revoluções". ${ }^{41}$ Maria Odila, entretanto, considerava o estudo da produção desses intelectuais brasileiros, vinculados majoritariamente ao projeto reformista, mais pertinente para o entendimento "das origens de uma cultura brasileira do que a análise das primeiras manifesta-

40 DIAS, Maria Odila da Silva. Aspectos da ilustração no Brasil. RHIGB, v. 278, 1968, p. 105-170.

41 BURMESTER, Ana Maria de Oliveira. A (des)construção do discurso histórico; a historiografia brasileira dos anos 70. Curitiba: Aos Quatro Ventos, 1997. 
ções revolucionárias e republicanas da colônia". ${ }^{42}$ Este comentário parece dirigir-se diretamente a Carlos Guilherme Mota, que, em 1967, defendera seu mestrado sobre "Idéia de Revolução no Brasil", que acompanhava, exatamente, estas manifestações. ${ }^{43}$ Pode-se considerar como um detalhe pleno de significações a publicação do artigo na Revista do Instituto Histórico e Geográfico Brasileiro. Segundo os diferendos políticos correntes na academia à época, este era mais um indício que reforçava o enquadramento do artigo como 'de direita'. Posteriormente, a historiadora passaria a integrar o consenso paulista, aproximando-se das idéias de Caio Prado Jr., em especial a de "sentido da colonização".

Nesse momento, tomava impulso uma historiografia construída no diálogo preferencial com a sociologia, o qual primava por privilegiar as noções de sistema que conjugavam, em doses diferentes, marxismo e estruturalismo. Não vale a pena reproduzir aqui as polêmicas resultantes da adoção de idéias concorrentes de sistemas (Escravistas, Coloniais, etc.). Basta lembrar que atualmente a historiografia, por exaustão, já abandonou esse debate. No quadro mais geral desta tendência, Fernando Novais tornar-se-ia o autor paradigmático. Sua tese de doutorado, defendida na USP em 1973, resultaria num Caderno do CEBRAP, publicado em 1974, e posteriormente em sua obra central: Portugal e Brasil na crise do antigo sistema colonial. ${ }^{44}$ Quando o autor tratou o tema do reformismo ilustrado luso-brasileiro, deu ênfase ao movimento memorialista do reinado de D. Maria, elencando o nome de alguns dos brasileiros oriundos da Coimbra Reformada, juntamente com as Memórias por eles produzidas. $\mathrm{O}$ interesse do autor, entretanto, era "indicar o clima geral do movimento ilustrado" e as "dominantes teóricas" que iriam orientar a política colonial relativa ao Brasil. Tendo como horizonte a questão da independência, Novais concluiu que as reformas não deram conta de aliviar as tensões crescentes, que o período de prosperidade não teria abrandado, mas antes, estimulado "o inconformismo dos colonos". No intuito de reforçar sua tese, Novais tendeu a fazer uma leitura teleológica dos textos por ele referenciados, descontextualizando-os do tempo em que foram produzidos para justificar acontecimentos situados no devir. ${ }^{45}$

42 DIAS, op. cit. p.105.

43 Ver MOTA, Carlos Guilherme. Atitudes de inovação no Brasil. 1789-1801. Lisboa: Livros Horizonte, 1972. MOTA, Carlos Guilherme. Idéia de revolução no Brasil (1789-180); estudo das formas de pensamento. Petrópolis: Vozes, 1979.

44 NOVAIS, Fernando A. Estrutura e dinâmica do antigo sistema colonial. (séculos XVI-XVIII) São Paulo: CEBRAP, 1974. e . Portugal e Brasil na crise do antigo sistema colonial. 1777-1808. São Paulo: Hucitec, 1979.

45 NOVAIS. Fernando A. O reformismo ilustrado luso-brasileiro: alguns aspectos. Revista Brasileira de História, n.7, 1984. p.105-118. O problema do anacronismo na abordagem proposta por de Novais não pas- 
Novais persistia num quadro historiográfico que ainda hoje se manifesta com fôlego, que é a tendência de vincular o estudo desses ilustrados brasileiros ao tema da independência. Alguns dos trabalhos relativos à porção luso-brasileira do Império costumam referenciar a segunda grande leva de cientistas brasileiros, egressos da Universidade de Coimbra Reformada, como a geração de $90^{46}$, salientando sua contribuição para o reconhecimento das potencialidades da colônia no âmbito de um projeto de recuperação econômica do Império, ou o protagonismo dessa elite instruída nas discussões em torno das idéias separatistas e do movimento que levaria à independência. Certos integrantes da intelectualidade brasileira do período vieram, de fato, a envolver-se com projetos políticos de cunho independentista e nacionalista. Contudo, esses estudos, por estarem voltados para aqueles brasileiros que se destacaram por sua atuação política, acabam por não registrar o legado que alguns destes, somados a um grupo alargado de cientistas brasileiros, vinham produzindo em nome de um projeto que articulava investigação científica com desenvolvimento econômico do Império como um todo. Se, efetivamente, dessa geração de estudantes de Coimbra saíram muitos dos que participaram de movimentos independentistas, também é verdade que a parcela mais expressiva desses intelectuais esteve perfeitamente afinada com as políticas metropolitanas ${ }^{47}$, as quais, sem perder de vista a questão do aproveitamento econômico dos produtos coloniais, visava o objetivo mais amplo de alinhar Portugal às demais potências européias em termos da produção de conhecimento científico sobre o mundo natural. Muitos deles, como José Bonifácio de Andrada e Silva, tornaram-se partidários da independência tão somente no apagar das luzes do Império.

Cumpre lembrar ainda uma vez que a formação universitária dos portugueses da América fazia parte de uma estratégia política de arregimentação das elites coloniais em prol de um projeto de fortalecimento do Império.

saria desapercebida e seria criticada à época. Ver, por exemplo, BOTTMANN, Denise. Ambigüidades do sistema colonial. História: Questões e Debates, v. 3, n. 5, 1982. p.141.

460 historiador Kenneth Maxwell, deteve-se no aspecto político de sua influência na formação do Império Luso-brasileiro, sem destacar do conjunto de alunos coimbrões aqueles que se tornaram viajantes pelo Império. MAXWELL, Kenneth R. The generation of the 1790's and the idea of a Luso-Brasilian Empire. In: DAURIL, Alden. Colonial roots of modern Brazil. Berkley: University of California Press, 1973. p. 107-44. A historiadora Maria Beatriz Nizza da Silva também referiu-se à mesma geração de 90 e à sua vinculação com a Inconfidência Mineira. Ver SILVA, Maria Beatriz Nizza da. (coord.) O Império luso-brasileiro; 1750-1822. Lisboa: Editorial Estampa, 1986. p.373 e ss.

47 Veja-se o caso de Lacerda e Almeida que não hesitou em denunciar o seu parceiro Antonio Pires da Silva Pontes às autoridades, por este dizer que "Minas Gerais / sua pátria/" deveria ser a "cabeça de um grande reino". AHU, Mato Grosso, Cx. 26, D1518. Ver PEREIRA e RIBAS, op. cit. p. 40. 
Conforme atestam as fontes, muitos dos cientistas brasileiros não abandonaram este compromisso com a política metropolitana, voltando seus diagnósticos sobre as colônias para esse objetivo. Se o conhecimento acumulado sobre o Brasil, nesse período, e os diagnósticos produzidos sobre suas potencialidades viriam a fomentar, posteriormente, as idéias de independência, não é verdade que essa perspectiva estivesse colocada desde o início. Muito pelo contrário, vistas em seu conjunto, as memórias produzidas pelos brasileiros sobre as várias regiões do Império denotam, antes, a eficácia de um projeto de reconhecimento sistemático das potencialidades de cada uma das colônias e de articulação política e econômica de Portugal com seus territórios ultramarinos. $\mathrm{O}$ caráter nitidamente reformista das propostas e planos de desenvolvimento expressos nas memórias produzidas pelos cientistas brasileiros, em perfeita consonância com as diretrizes vigentes na metrópole, não dá lugar a pensar qualquer intenção de ruptura.

Sabe-se que essa intelectualidade, embora nutrisse amplas expectativas em relação ao 'progresso' e ao desenvolvimento econômico da colônia do Brasil, pertencia a uma elite que, via de regra, seguia padrões de lealdade à coroa, da qual era 'servidora'. Grande parte desses colonos ilustrados, copartícipes das políticas da metrópole, estava longe de nutrir qualquer 'inconformismo' de cunho independentista. Entre privilégios e interesses de elite e desejos de independência, havia um longo caminho a ser percorrido.

Todavia, cada vez mais a produção historiográfica brasileira tinha dificuldade em lidar com a questão. Grande parte dos falsos problemas então criados derivava de um quadro teórico-metodológico dominante nas universidades, o qual fundia marxismo com nacionalismo extremado. Em nome de um nacionalismo teleológico, que deveria ter existido antes mesmo da nação, houve historiadores que criticaram abertamente toda essa geração de luso-brasileiros por terem trabalhado "para" os portugueses, como se tal crítica fizesse algum sentido. Um comentário, da década de 1970, sobre a atuação de Alexandre Rodrigues Ferreira pode ser tomado como síntese exemplar deste tipo de perspectiva historiográfica. Tudo o que nele é dito sobre o naturalista baiano poderia ter sido dito sobre a maior parte dos luso-brasileiros que trabalharam para a coroa portuguesa.

Rodrigues Ferreira, em resumo, não é certamente um libertário nem, sequer, um crítico moderado das condições sociais de vida do seu tempo. Apesar de ter, como nascido na colônia, pago um preço não pequeno à odiosa ordem maniqueísta do mundo colonial, o naturalista curva-se e serve. Em nenhum momento pode-se captar nele indícios dos anseios de liberdade e progresso que possuíam seus colegas coloniais em Coimbra, Montpellier ou outras 
universidades européias. Alexandre Rodrigues Ferreira aceitou passivamente a continuidade da situação colonial no momento mesmo em que o sistema estava em crise final. ${ }^{48}$

É preciso ter em conta que, atualmente, é bastante contestada a idéia da existência de uma crise sistêmica ${ }^{49}$, que teria conduzido inelutavelmente à ruptura do pacto colonial. ${ }^{50}$ Outra suposição sem maiores fundamentos é a de que havia perseguição ou má vontade da coroa em relação aos naturais das colônias. Além disso, nem Coimbra, nem Montpellier foram exatamente celeiros de inconfidentes. Por fim, Lacerda e Almeida, Silva Feijó, Silva Pontes, Rodrigues Ferreira, Andrada e Silva e tantos outros são exemplos que contrariam frontalmente a noção de que existiria uma "odiosa ordem maniqueísta do mundo colonial". As trajetórias de praticamente todos os intelectuais integrantes dessas gerações de colonos ilustrados se deram sob os auspícios régios. Além do que, no desempenho de suas funções, sentiram-se bastante livres para tecer críticas severas à atuação colonial dos 'portugueses', entre os quais eles próprios se incluíam. Quase todos os letrados formados em Coimbra se consideravam portugueses da América, leais súditos da coroa e estavam diretamente envolvidos na criação de um "Grande Império", no qual coubesse às elites coloniais uma fatia de poder. Nesse sentido, o trabalho da historiadora Maria de Lourdes Viana Lyra trouxe um contributo original para se pensar a permanência da idéia de Império, entre as elites políticas do Brasil, mesmo após a emancipação da colônia. ${ }^{51}$

\section{A onda dos viajantes}

Numa outra linha de estudos, certo modismo acadêmico mundial trouxe à cena da historiografia brasileira o viajante e as viagens como tema de investigação autônoma. Pela riqueza de informações e possibilidades de abordagem que sugerem, as narrativas de viagem tornam-se um tema caro aos pesquisadores de origem européia e norte-americana. No Brasil, o fenômeno ganhou força principalmente na década de 70, em grande medida

48 MOREIRA NETO, Carlos de Araújo. Introdução. In: FERREIRA, Alexandre Rodrigues. Viagem Filosófica ao Rio Negro. Belém: Museu Paraense Emílio Goeldi, 1983. p. 36.

$49 \mathrm{Tal}$ como foi desenvolvido em NOVAIS, Fernando A. Estrutura e dinâmica do antigo sistema colonial. (séculos XVI-XVIII) São Paulo: CEBRAP, 1974. e . Portugal e Brasil na crise do antigo sistema colonial. 17771808. São Paulo: Hucitec, 1979.

50 Ver, por todos, ALEXANDRE, Valentim. Os sentidos do Império; Questão nacional e questão colonial na crise do Antigo Regime português. Porto: Afrontamento, 1993.

51 LYRA, Maria de Lourdes Viana. A utopia do poderoso império. Rio de Janeiro: Sete Letras, 1994. 
devido à edição das coleções bibliográficas anteriormente mencionadas. No entanto, aqui, mais uma vez, é notável a repercussão e a preferência já assinalada pelos textos dos viajantes do século XVI e, principalmente, do século XIX. Em ambos os casos, viajantes estrangeiros que aqui estiveram.

O mesmo não se pode dizer em relação aos viajantes brasileiros do setecentos. A decantada grandiosidade da viagem filosófica de Alexandre Rodrigues Ferreira à Amazônia, vista como acontecimento singular, mereceu uma profusão de estudos de historiadores d'aquém e d'além mar. ${ }^{52}$ No entanto, o olhar historiográfico permaneceu desatento para a atuação dos demais cientistas brasileiros do século XVIII que, simultaneamente a Alexandre Rodrigues Ferreira, realizavam expedições em outras porções do Império, com os mesmos objetivos e sob a mesma orientação do mestre de História Natural da Universidade de Coimbra, Domingos Vandelli.

É sempre bom lembrar que foi preciso um autor norte-americano para que a viagem filosófica de Rodrigues Ferreira fosse percebida como parcela integrante de um projeto mais amplo de explorações científicas promovido pela coroa portuguesa. ${ }^{53}$ Foi Joel Simon o primeiro autor a costurar com alguma substância a atuação conjunta de Ferreira, Manuel Galvão da Silva, João da Silva Feijó e José Joaquim da Silva, os luso-brasileiros que estagiaram nos Jardins do Palácio da Ajuda antes de partirem, em 1783, respectivamente para a Amazônia, Moçambique, Cabo Verde e Angola.

A obra, no entanto, não teve maiores impactos no Brasil, principalmente devido ao seu recorte nada 'brasileiro'. Pouco interessou aos nossos estudiosos a amplitude do processo de viagens científicas envolvendo luso-brasileiros e colônias portuguesas não americanas. Entre os estudiosos brasileiros ainda prevalece o entendimento anacrônico de que ao viajarem pra a África ou para a Ásia portuguesa, os luso-americanos dirigiam-se ao 'exterior' ou ao 'estrangeiro'. Na vertente brasileira do modismo acadêmico do estudo dos relatos de viajantes, o que interessava eram as peregrinações realizadas por estrangeiros através do Brasil. Veja-se, por exemplo, o sempre citado dossiê Brasil dos Viajantes, publicado pela Revista USP em 1996. A publicação tinha por objetivo primário "debater sob prisma interdisciplinar a construção de imagens do Brasil e da América por artistas, cronistas e cien-

52 Ver DOMINGUES, Angela. Viagens de exploração geográfica na Amazónia em finais do século XVIII: política, ciência e aventura. Funchal: Centro de Estudos de História do Atlântico, 1991. Nesta obra está relacionada ampla bibliografia sobre Alexandre Rodrigues Ferreira, tanto de origem portuguesa quanto brasileira.

53 SIMON, Joel William. Scientific expeditions in the portuguese overseas territories; 1783-1808. Lisboa: Instituto de Investigação Tropical, 1983 
tistas estrangeiros que percorreram o continente desde o século XVI". ${ }^{44}$ Este recorte primário dos viajantes estrangeiros foi rompido apenas pela presença do naturalista luso-brasileiro Alexandre Rodrigues Ferreira, que se infiltrou, sorrateiramente, na coletânea. A concessão foi feita para que o século XVIII não ficasse vazio em um dossiê que se propunha a cobrir o Brasil desde o descobrimento.

Na década de 1990, persistia o engano historiográfico de eleger as viagens exploratórias do século XIX como ponto de partida das iniciativas de caráter científico de reconhecimento do Brasil. o historiador Francisco Moraes Paz afirmaria então que "excluída a expedição de Alexandre Rodrigues Ferreira à Amazônia (1783-92) e outras de menor relevância”, a América portuguesa teria sido alvo de conhecimento científico "unicamente após a transferência da Corte para o Rio de Janeiro". ${ }^{55}$ Do período anterior, Paz registraria as viagens de Georg Marcgrav e Willem Piso, que estudaram o Pernambuco holandês, deixando um grande vazio a ocupar o tempo entre as explorações promovidas por Nassau e a vinda da missão francesa, em 1816. Como temos visto, este intervalo é fruto de uma construção historiográfica.

Refletindo sobre a tradição da viagem no processo de constituição da cultura ocidental, Paz indicou o contributo de algumas narrativas. "Quanto às impressões ocidentais sobre a África", o autor lembrou o escocês Mungo Park, e os ingleses Livingstone e sir Richard Burton. ${ }^{56}$ Se os diários da atribulada e fatal viagem do brasileiro Francisco José de Lacerda e Almeida ${ }^{57}$, iniciada em 1797, ao interior africano tivesse tido a mesma divulgação (e atenção historiográfica) que as narrativas dos citados viajantes estrangeiros, certamente Paz teria tido a oportunidade de valorizar a experiência vivida e as impressões desse colono viajante sobre a África. Cerca de meio século antes de Livingstone, o nosso 'viajante-herói' encontraria a morte ao tentar realizar o almejado projeto português de fazer a viagem a contracosta, partindo de Moçambique em direção a Angola. Pioneirismo que aquele mesmo Sir Richard Burton viria a reconhecer.

54 BELLUZO, Ana Maria. A propósito d'O Brasil dos viajantes. Revista USP, Dossiê Brasil dos viajantes. n.30, 1996. p.10.

55 PAZ, Francisco Moraes. Na poética da história, a realização da utopia nacional oitocentista. Curitiba: Editora da UFPR, 1996. p. 204.

56 PAZ, op. cit. p.198.

57 o conjunto dos diários de viagem de Francisco José de Lacerda e Almeida, que inclui os diários relativos aos dez anos de viagem do matemático pelos sertões do Brasil, foi publicado em 1944, com nota-prefácio de Sergio Buarque de Holanda. ALMEIDA, op. cit. 
Until Dr. Livingstone shall have returned from his third expedition, the writings of Dc. Lacerda must continue to be our principal authority, and only from them the reader can at present learn where the English traveller is said to have been detained..$^{58}$

Cumpre fazer a ressalva de que Francisco Paz não era um especialista do tema das viagens, da Ilustração ou das ciências. Nada disto era o assunto principal de seus estudos. Assim, ele apenas coligiu e reproduziu noções recorrentes na tradição historiográfica brasileira, reafirmando idéias de ampla aceitação, as quais vimos tentando acompanhar.

Dois pontos chamam a atenção sobre o conjunto dos trabalhos que transmitem este tipo de informação. O primeiro é que quase todos eles restringem a atuação dos cientistas coimbrões à parte brasileira do Império. Resulta daí, minimizar a dimensão transcolonial da sua atuação que, efetivamente, extrapolou os limites das colônias americanas. Perceber essa dimensão significa ampliar a compreensão do papel desses viajantes brasileiros, inscrevendo-os nos quadros de uma política imperial mais ampla, que contemplava a articulação do Brasil com as demais colônias portuguesas, especialmente as da África. O segundo aspecto é que, mesmo aqueles estudos que procuram pontuar a atuação dos cientistas brasileiros nas expedições do iluminismo português, dispensam pouca atenção ao estatuto desse viajante. Parece, entretanto, ser este o ponto que permite distinguir e dar relevo ao personagem, destacando-o do conjunto de informantes mobilizados pela coroa na atividade de reconhecimento dos domínios coloniais a partir da segunda metade do século XVIII até início do XIX.

O sigilismo da coroa portuguesa sobre as informações relativas a seu território na América talvez possa explicar o pouco interesse em divulgar, na época, os resultados das investigações científicas realizadas pelos viajantes brasileiros; mantidos como documentos político-administrativos de caráter estratégico. Contudo, esses documentos, muitos deles publicados, estão, hoje, acessíveis aos estudiosos, não justificando, assim, o silêncio historiográfico em torno de toda uma geração de cientistas envolvida com o esforço português de re-descobrir suas colônias à luz da ciência através das viagens filosóficas e do movimento memorialista induzido pela Academia das Ciências de Lisboa. Desprezar as viagens científicas da Ilustração portuguesa

58 BURTON, R. F. (ed.). Lacerda's Journey to Cazembe in 1798. In: The lands of Cazembe. London: John Murray, 1873. p.11. Até o Dr. Livingstone ter retornado de sua terceira expedição, os escritos do Dr. Lacerda continuaram a ser nossa principal fonte, e somente através deles o leitor podia, até o presente, saber até onde o viajante inglês havia chegado. (Tradução livre de nossa autoria) 
pode levar a dois tipos de equívoco. Primeiro, o de tomar como verdadeira a afirmação de que as primeiras informações relevantes de caráter científico produzidas sobre o Brasil fora obra dos viajantes estrangeiros, no século XIX. Segundo, mas não menos importante, o de perder a perspectiva de que esse conhecimento científico estava sendo gerado, por cientistas nascidos no Brasil, simultaneamente em várias regiões do Império e, portanto, fazia parte de uma política articulada com alcance e dimensões muito maiores do que faz supor a memorável viagem filosófica de Alexandre Rodrigues Ferreira.

Uma linha de investigação relativamente recente tem dado importantes contribuições para alterar as bases do conhecimento do conjunto da produção dos cientistas brasileiros do setecentos. Na tradição historiográfica de Charles. Boxer ${ }^{59}$, tem ganhado força a idéia de estudar o Brasil colônia em articulação com o restante do Império colonial português. As teses de que o Brasil se formou para além dos limites de suas fronteiras territoriais e, no contexto das políticas metropolitanas, em consonância com um projeto de amplitude imperial, encontra defensores em autores como Alencastro e Fragoso. ${ }^{60}$ Registre-se o fenômeno editorial, que atualmente tornou-se corrente, de organização de coletâneas que visam, agregar o trabalho de pesquisadores que vêm pensando o Brasil colônia no âmbito do Império português. ${ }^{61} \mathrm{O}$ presente artigo, igualmente, tem como um dos argumentos de sustentação a idéia de que a intelectualidade colonial, na qualidade de agente das políticas imperiais, deve ser apreendida na sua atuação transcolonial. Ademais, é no contexto da política imperial que deve ser lida a produção intelectual dessa elite viajante que postulava o 'progresso' e a 'modernização’ do Brasil, sim, mas como parte integrante do Império e não em contraposição a ele.

O exclusivismo do estudo dos viajantes europeus que por aqui circularam, tão característico da historiografia das décadas de 1970 e 1980, passa, a partir de meados da década de 1990, a dar algum espaço aos luso-brasileiros ilustrados. O fenômeno é perceptível tanto através da constituição de novos

59 BOXER, C. R. O Império Colonial Português. 1415-1825. Lisboa: Edições Setenta, 1981.

60 FRAGOSO, João. Homens de grossa aventura: acumulação e hierarquia na praça mercantil do Rio de Janeiro, 1790-1830. Rio de Janeiro: Arquivo Nacional, 1992. ALENCASTRO, Luis Felipe. O trato dos viventes; formação do Brasil no Atlântico Sul. São Paulo: Companhia das Letras, 2000.

61 Esta "tradição" historiográfica, que até hoje dá imensos frutos, iniciou com FRAGOSO, João et al. 0 Antigo Regime nos trópicos, a dinâmica imperial portuguesa (séculos XVI-XVIII). FURTADO, Júnia F. (org.) Diálogos oceânicos: Minas Gerais e as novas abordagens para uma história do Império Ultramarino Português. Belo Horizonte: Editora da UFMG, 2001. História, Questões \& Debates. Império português: ciência, poder e sociedade. v.19, n.36, 2002. 
grupos de pesquisa quanto pela difusão da temática entre os pesquisadores de instituições consolidadas. No Rio de Janeiro, o interesse pela temática espalhou-se por diversas universidades e centros de pesquisa, em especial a Casa de Oswaldo Cruz. Em São Paulo, no Instituto de Geociências da Unicamp, os pesquisadores que se dedicavam especialmente à história da geologia assumiram uma atitude militante de defesa e propagação de seus temas de estudo, participando ativamente de eventos científicos em diversos países. Muitos dos ex-alunos, oriundos daquele programa de pós-graduação, acabaram por dar continuidade ao estudo de suas temáticas em outras instituições de ensino superior. Já na capital paulista, a matéria foi explorada por diversos pesquisadores reunidos no Centro Simão Mathias de Estudos em História da Ciência, da PUC/SP. Fora do eixo Rio-São Paulo, é preciso mencionar a produção do CEDOPE, em Curitiba, na qual estamos envolvidos.

Em Portugal, os anos 90 também representaram uma retomada no estudo da história das ex-colônias, no qual se inclui o tema das viagens científicas do período. Boa parte das pesquisas sobre a matéria desenvolveram-se no IICT e também no CHAM, da Universidade Nova de Lisboa e no CEHFCI, da Universidade de Évora. ${ }^{62}$

Ao chegarmos ao século XXI, é possível observar um grande incremento no estudo do ambiente ilustrado português, tanto no Brasil, quanto em Portugal. A produção acadêmica que antes se concentrava em alguns poucos núcleos agora espalha-se por dezenas de universidades e centros de pesquisa. A ampliação do campo editorial universitário fez com que, a cada mês, apareçam novos artigos que tratam direta ou indiretamente do assunto. ${ }^{63}$ Além disso, praticamente não há mais nenhum ilustrado luso-brasileiro que não tenha sido objeto de uma dissertação de mestrado ou tese de doutorado. Os múltiplos projetos de pesquisa e defesas de pós-graduação também tiveram impacto no mercado editorial. São cada vez mais freqüentes os lançamentos de livros sobre o tema.

Diga-se, também que o crescimento desta produção historiográfica mais recente não é apenas qualitativo, mas é também quantitativo. Outro fenômeno importante a perceber é que tal produção, agora, ocorre dentro de um processo de integração inter-regional e internacional. Núcleos de

62 Respectivamente, Instituto de Investigação Científica Tropical, Centro de História do Além-Mar e Centro de Estudos de História e Filosofia da Ciência.

63 Veja-se a coleção Ciência \& Império recentemente lançada pela Editora da UFPR, que já publicou volumes monumentais sobre João da Silva Feijó e Francisco José de Lacerda e Almeida e tem no prelo outros, sobre Elias Alexandre da Silva Correia, Luís Antônio de Oliveira Mendes, Alexandre Rodrigues Ferreira, etc. 
estudo que antes tendiam ao isolamento, no Brasil e em Portugal, passaram a dialogar entre si, o que pode ser observado pelo cruzamento das citações bibliográficas. Desta forma, a maior parte dos trabalhos já parte do domínio de uma conjuntura que, em suas linhas mestras, está estabelecida, não sendo mais necessário reinventar a roda a cada início de pesquisa.

\section{Revendo o Revisionismo}

Apesar do aumento do interesse e conseqüente crescimento do número de estudos sobre as investigações científicas e as viagens setecentistas iluministas no universo luso, é importante chamar a atenção para um detalhe que tem escapado à maior parte dos autores: o fato de que estes cientistas eram oriundos dos espaços coloniais. À primeira vista, a preocupação pode parecer como algo dado de antemão e até desimportante. Pode mesmo ser interpretada como uma recaída no nacionalismo historiográfico, anteriormente criticado. Todavia, tal detalhe tem conseqüências metodológicas e epistemológicas importantes, que não podem ser menosprezadas.

Lembremos que o grosso da literatura sobre o tema da história da ciência e das viagens científicas foi produzido na França e nos países anglo-saxões, os quais não conheceram o fenômeno do colono viajante na amplitude em isto ocorreu no universo ibérico. Nesta literatura, a exploração científica da natureza costuma aparecer em mão única: o viajante europeu percorrendo terras até então "desconhecidas". Este acabou sendo o pressuposto metodológico de fundo para quase toda a historiografia sobre viagens científicas. Mais recentemente, difundiram-se nesses países correntes revisionistas, quase sempre com vínculos políticos com as ditas 'minorias'. ${ }^{64}$ Outros núcleos de estudos revisionistas aparecem nas áreas de lingüística e de estudos literários. ${ }^{65} \mathrm{~A}$ antropologia também produziu importantes estudos de revisão sobre encontros civilizacionais e a 'descoberta do outro'. ${ }^{66}$ Todavia, os revisionismos antropológicos, sociológicos, lingüísticos, etc. originários do universo intelectual francês e anglo-saxão continuam firmemente ancorados aos respectivos pensamentos imperialistas nacionais que partem da seguinte premissa: o conhecimento do mundo é o conhecimento anglo-francês do mundo.

64 A obra vinculada a essas correntes revisionistas com maior impacto no Brasil é PRATT, Mary Louise. Os olhos do império; relatos de viagem e transculturação. Bauru: Edusc, 1999.

65 Ver, em especial, TODOROV, Tzvetan. As morais da história. Lisboa: Publicações Europa-América, s.d. 66 Ver SAHLINS, Marshall. Ilhas da História, Rio de Janeiro, Zahar, 1988. 
Autores de primeira linha, como Sahlins ou Todorov, têm enfrentado o tema dos contatos culturais com acuidade e sofisticação metodológica. No entanto, há toda uma plêiade de autores de segunda linha que são presas fáceis do viés analítico da "descoberta do outro", o qual acaba por ser pouco operacional para fenômenos do século XVIII e início do XIX. Nos casos de Espanha e Portugal, o período representava mais de 200 anos de dominação, convívio e mestiçagem. Nos casos da França, Holanda e Inglaterra, pouco menos que isso. Viajantes como Lapérouse, apesar de francês de nascimento, era um homem das colônias, casado como uma creóle. Também creóle, nascida na Martinica, era a Imperatriz Josefina que estava profundamente envolvida com os processos de aclimatação de animais e plantas americanas na Europa. Cook, no Pacífico, foi antes a exceção do que a regra. Em graus diversos, que em ordem crescente vai de Portugal, Espanha, França à Inglaterra, o conhecimento científico do mundo, em moldes iluministas, teve ampla participação dos leigos das colônias, quando não por cientistas viajantes nascidos nas colônias, ou nelas há muito radicados. 0 estranhamento exagerado (nós X os outros) é antes um efeito literário, produzido deliberadamente pelos relatos de viagem, do que um 'fato científico'. Havia nisto uma dupla estratégia. Do ponto de vista da literatura, os autores buscavam atiçar no leitor o interesse pelo exótico e pela novidade, algo muito característico deste gênero literário desde o seu surgimento na antiguidade. ${ }^{67}$ Do ponto de vista das estratégias imperiais, ao negar o secular contato e insistirem na idéia dos descobrimentos, Inglaterra e França estavam afirmando que eles haviam assumido o papel que outrora fora dos portugueses e espanhóis e, portanto, a eles cabiam os novos territórios 'recém-descobertos'.

Como já afirmamos, no período em questão, a polaridade entre europeu e nativo há muito havia desaparecido. No entanto, a oposição primária entre culturas, raças, gêneros, etc. tem público certo entre os cultores de certos revisionismos, que preferem lidar com um mundo simplificado, feito de maniqueísmos rasteiros: exploradores X explorados, europeus X nativos, negros X brancos, etc. X etc. Para entendermos o mundo do século XVIII, feito de populações vivendo secularmente 'em contato', é preciso desconstruir, complexificando, os esquemas bipolares e simplistas - nós e os outros - que têm servido de base metodológica e epistemológica para historiadores,

67 PIMENTEL, Juan. Testigos del mundo; Ciencia, literatura y viajes em la ilustración. Madrid: Marcial Pons, 2003. p. $41-42$. 
antropólogos, lingüistas, etc., inclusive para aqueles que se propõem a fazer abordagens vinculadas aos estudos culturais e pós-coloniais. ${ }^{68}$

Por seu apego às polaridades redutoras, essas vertentes revisionistas dificilmente conseguem dar conta da singularidade das questões postas pelo estudo do colono-cientista-viajante luso-brasileiro. Assim, autores representativos desses vieses analíticos podem apontar algumas correções de caminhos mas não são capazes de lidar com a complexidade de nossa problemática, por não conseguirem afastar-se dos referenciais teóricos correntes na Europa e na América do Norte. Sabemos nós que portugueses e espanhóis haviam 'inventado o mundo' desde o século XVI. Ao menos parte significativa desse mundo que os naturalistas franceses, ingleses, suecos ou alemães estavam visitando e divulgando nos séculos XVIII e XIX. Quando eles viajavam pelo 'desconhecido', freqüentemente estavam fazendo incursões pelas colônias e ex-colônias 'do outro', no caso espanholas e portuguesas. Este simples fato escapou a diversos autores que tem procurado enfrentar teoricamente a natureza dos contatos e da transferência de conhecimentos que se davam nas regiões de expansão européia. É compreensível que ingleses e franceses disseminassem tal noção no século XVIII. Mas o que dizer do sociólogo Bruno Latour, que candidamente não vê problema em comparar D. João I de Portugal e seus navegadores, no século XV, a Luís XVI e Lapérouse no XVIII? ${ }^{69}$

A noção de "zona de contato", aprimorada por Mary Louise Pratt, também procura dar conta destes encontros provocados pela expansão européia. ${ }^{70}$ No entanto, ainda que cheia de intenções revisionistas, a autora mantém-se estritamente no imaginário da oposição bimária dos encontros primevos entre civilizações e, mais que isso, no quadro do pensamento imperial britânico. Pratt não tem a menor dificuldade em afirmar que W. B. Stenvenson "exagerou apenas um pouco" ao dizer, em 1825, que, "sem o menor exagero", embora as terras da América do Sul "tenham sido descobertas

68 Ver PEREIRA, Magnus R. M. "Las cosas singulares de piedras, animales, plantas”: la formación y el funcionamiento de la red imperial española de remesas centíficas en el Virreinato del Río de la Plata. Anais do Museu Paulista, v. 21, 2013. p.116-132.

69 LATOUR, Bruno. Ciência em ação: como seguir cientistas e engenheiros sociedade afora. São Paulo: Unesp, 2000. p. 362.

70 PRATT, op. cit., p.32. Os problemas do conceito de zona de contato, tal como o emprega Pratt, não escaparam à reflexão de Londa Schiebinger, para quem o seu uso tem levado a uma noção excessivamente rígida dos não-europeus como "outros". SCHIEBINGER, Londa. European naturalists in the West Indies. In: SCHIEBINGER, L. e SWAN, C. Colonial Botany; Science, commerce, and politcs in the Early Modern World. Philadelphia: University of Pensilvania Press, 2005. p.125 e ss. 
no século XVI, permaneceram quase desconhecidas até o começo do XIX". ${ }^{71}$ Desconhecidas em que termos? ou para quem? é preciso perguntar à autora.

A experiência portuguesa é simplesmente ignorada pela historiografia inglesa e francesa e com ela a ação dos viajantes do iluminismo luso. Nos pensamentos imperiais anglo-saxão e francês é um detalhe insignificante que no mesmo processo em que J. Cook e Bougainville travavam seus primeiros contatos com os desconhecidos "Mares do Sul" e Mungo Park adentrava o território africano, viajantes brasileiros estavam fazendo viagens filosóficas nos territórios do Brasil e da África onde a administração portuguesa já se encontrava secularmente assentada. ${ }^{72}$ Uma porção expressiva do mundo que seria visitado pelos "viajantes europeus", do iluminismo e, mais tarde, pelos cientistas do romantismo, já fora percorrida e intelectualmente elaborada por gerações de estudiosos oriundos das elites coloniais locais ou de outras colônias, alguns deles mestiços.

Como se percebe, nos esquemas de pensamento de uma parte expressiva de autores europeus e norte-americanos não há espaço para situações como as dos colonos-viajantes-naturalistas-ilustrado luso-brasileiros. Portanto, não adianta chamar essa historiografia para elaborar teoricamente tal figura-tipo. É preciso entender que a importância da questão extrapola a sua abrangência regional, o Brasil ou império luso-brasileiro, para se tornar uma questão mais ampla que diz respeito à historiografia das ciências, da história do pensamento ou das idéias. Não se trata de pugnar pela simples inclusão de brasileiros esquecidos no rol dos viajantes do século XVIII, uma questão de cunho meramente nacional. A questão é tentar desconstruir, complexificando, os esquemas bipolares simplificadores - nós X os outros que têm servido de base metodológica e epistemológica para historiadores, antropólogos, lingüistas europeus e norte-americanos, os quais são avidamente reproduzidos pela desavisada historiografia brasileira. ${ }^{73}$

Artigo recebido para publicação em: 16/07/2013

Artigo aprovado para publicação em: 31/10/2013

\footnotetext{
71 PRATT, op. cit. p.251-2.

72 Não há, portanto, em suas narrativas, o estranhamento que aparece nos relatos europeus.

73 Trabalhos pioneiros nessa vertente são CRUZ, Ana Lúcia R. B. Verdades por mim vistas e observadas, oxalá foram fábulas sonhadas. Cientistas brasileiros do setecentos, uma leitura auto-etnográfica. Curitiba: UFPR, 2004. (tese de doutorado policopiada) e CRUZ, Ana Lúcia R. B. As viagens são os viajantes; dimensões identitárias dos viajantes naturalistas brasileiros do século XVIII. História: Questões \& Debates, n.36, 2002. p.61-98.
} 